\title{
Toxicology of Commonly Found Ingredients in E-Cigarettes: A Brief Review
}

\author{
Hussam Z. Alshareef ${ }^{1}$, Stanley T. Omaye ${ }^{1,2^{*}}$ \\ ${ }^{1}$ Environmental Science Graduate Program, University of Nevada, Reno, USA \\ ${ }^{2}$ Department of Nutrition, University of Nevada, Reno, USA \\ Email: sam.alshareef@nevada.unr.edu, *omaye@unr.edu
}

How to cite this paper: Alshareef, H.Z. and Omaye, S.T. (2021) Toxicology of Commonly Found Ingredients in E-Cigarettes: A Brief Review. Health, 13, 1396-1409. https://doi.org/10.4236/health.2021.1311100

Received: October 16, 2021

Accepted: November 27, 2021

Published: November 30, 2021

Copyright $\odot 2021$ by author(s) and Scientific Research Publishing Inc. This work is licensed under the Creative Commons Attribution International License (CC BY 4.0).

http://creativecommons.org/licenses/by/4.0/

\begin{abstract}
Electronic cigarettes (EC) have gained popularity among smokers due to their taste, smell, appearance, and easy availability compared to traditional cigarettes, as well as the perception that they are safer than traditional cigarettes. These devices result in aerosols containing nicotine, propylene glycol, glycerin, ethylene glycol, vitamin E, and chemical flavors inhaled into the lungs. Other components found in these vapors include heavy metals such as nickel, chromium, lead, manganese, and tin. In addition, some ingredients volatilization leads to toxic aldehydes formation such as formaldehyde, acetaldehyde, and acrolein. Smoking cigarettes is addictive and has been associated with many health issues such as heart disease, lung cancer, etc. Rising awareness of these dangers moves more people towards these electronic delivery systems, reducing the health effects of cigarettes. The toxicity of EC's ingredients is well studied when ingested; however, their toxicity through inhalation remains unclear. Consequently, the use of ECs has become a significant concern worldwide and raises whether it is indeed safe to use. This paper will serve as a literature review paper to discuss the toxicity of commonly found ingredients in ECs and their associated health issues. Our conclusion emphasizes that even though smoking EC is less risker than smoking traditional cigarettes, it is still not safe due to the potentially harmful effect these E-cig's ingredients have on the human's health. In addition, E-cigarette's aerosol could also contain toxic compounds such as formaldehyde, acetaldehyde, and acrolein due to glycerin's thermo-degradation.
\end{abstract}

\section{Keywords}

Nicotine Delivery Systems, Electronic Cigarettes, Vapping, E-Cigarettes, Nicotine, Smoking 


\section{Introduction}

Electronic cigarettes (EC) are often referred to as e-cigarettes, personal vaporizers, electronic smoking machines, and electronic nicotine delivery systems. These devices are sold as a safer alternative to traditional cigarettes (TC), in which pure nicotine is administered to the lungs with only harmless water vapor as a byproduct. The system removes the need to burn tobacco to get nicotine; instead, it delivers it as an inhaled aerosol with other ingredients. The elimination of burned tobacco has been linked to the devices' reduced health effects, which manufacturers strongly promote [1].

The use of ECs has increased dramatically in the last decade. Vaping devices are the most common type of nicotine abuse in the United States, particularly among teenagers [2]. Fast availability, look diversity, and flavor varieties have all been linked to a growth in the spread of these devices. Electronic nicotine distribution systems can take on various shapes and sizes, including thumb drives, pipes, cigars, and the form of traditional cigarettes [3]. Furthermore, the perception that ECs are safer than TCs has increased their popularity, especially among the younger generation.

All ECs share the same primary functionality regardless of their sizes/shapes. The general EC's compounds are cartridge, atomizer, sensor, and lithium battery (Figure 1). The cartridge is where e-liquid is held and heated to a vapor that can be inhaled quickly. The atomizer and the electrical control for forming vapor are housed in the vaporization chamber, a hollow tube. Before using the unit, the vaporization chamber should be connected to the cartridge containing the e-liquid, whose end acts as the mouthpiece. The atomizer, typically formed like a coil, serves as the heating element for the e-liquid. The atomizer and the e-liquid are housed in the cartridge, heating the solvent to create an inhaled aerosol. Once a person inhales, as they would to a regular cigarette, the sensor triggers, causing the atomizer to heat the e-liquid in the cartridge. Some of these devices are refillable with vape juice, and others are disposable.

Furthermore, since the devices' usage is still relatively recent, no uniform model has been developed. As a result, EC devices can be split into four generations. First-generation represented by disposable e-cigs, while e-cigs with prefilled

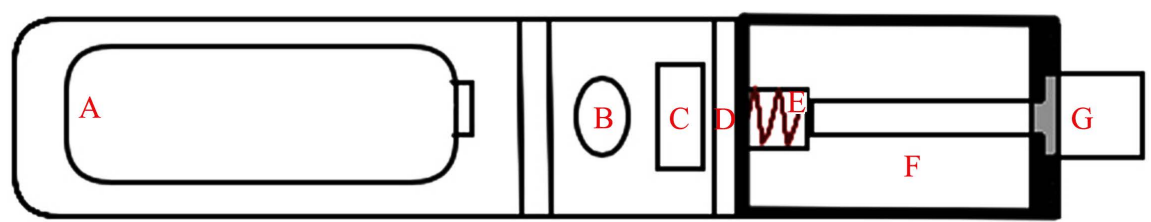

Figure 1. Overall of general E-cigarette compounds. A: The battery: serves as a source of power. B: Activation button: leads to the sensor activation when it is pushed. C: Display screen: provides information about the device settings. D: the Sensor turns on when activation button is pushed. In devices without activation button, sensor will turn on when the user inhales. E: The atomizer: a coil serves as a heating element to convert e-liquid to aerosol. F: The cartridge: where e-liquid is hold. G: the mouthpiece: where a user inhales the aerosol. 
or refillable cartridges represent the second-generation. The third-generation is refillable tanks or mods, and the last generations are those prefilled or refillable pod mods such as JULL deviced [4].

Despite both ECs and TCs contain tobacco products, they are undoubtedly different. E-cigs are much less hazardous than traditional ones. The main difference between the two is the presence of tobacco in TCs which is absent in ECs. As cigarettes are burnt, they emit approximately 7000 chemicals, many of which are poisonous; at least 69 of these chemicals cause cancer, according to the American Lung Association. On the other hand, there are fewer carcinogens in ECs due to the elimination of tobacco. Yet, ECs contain a high concentration of ultrafine particles and toxicants, increasing the risk of non-cancerous lung disease and cardiovascular disease [5].

The debate of whether smoking ECs is safer than smoking TCs despite their adverse effects is still rife as ECs are supposed to be another option for smokers. The aerosol found in vaping devices contains fewer toxic chemicals than the mixture of around seven thousand chemicals found in cigarettes [6]. However, the vapor contains nicotine, propylene glycol, glycerol, ethylene glycol, vitamin E, chemical flavors, and heavy metals such as lead, tin, nickel, chromium. In terms of health issues associated with the use of ECs, there are some well-known health effects of ECs, including, but not limited to, lung injury, cancer, heart diseases, and respiratory diseases.

\section{Lung Injury}

The windpipe is attached to the lungs via small branches and the alveoli via tiny capillaries in a healthy person's respiratory system, where oxygen and carbon dioxide are exchanged. Any minor changes disturbing the prefect environmental conditions in the lungs could lead to lung injury, as in E-cig. Unfortunately, ECs have been linked to lung inflammation, leading to respiratory failure and death ultimately. E-cigarette or vaping use-associated lung injury (EVALI) can manifest differently among individuals with common symptoms such as severe lung damage, inflammation, and respiratory failure, which can be fatal. There is not enough evidence to exclude other contaminants in ECs as possible causes of EVALI events, as the disease is now established [7].

\section{Cancer}

Due to over seventy carcinogens in the smoke, ECs have been linked to a variety of cancers. However, it would make sense to expect cancer risk to decrease due to the absence of tobacco in ECs compared to TCs. However, there is uncertainty in the carcinogen of other components found in these devices, such as humectants and flavorings present in ECs. Exposure to EC vapor was shown to cause lung cancer in mice, and symptoms of early stages of bladder cancer were visible in the animals, according to findings from the National Institute of Environmental Health Science [8]. The connection between ECs and cancer is a relatively recent subject, and there is limited information available. As a result, it is essential to realize that these results can be readily repeated on humans over a long period. New York University School of Medicine researchers discovered 
that 12 weeks of exposure to the aerosol caused DNA damage in the bladder, heart, and lungs [8]. According to the available data, vaping is linked to an elevated risk of cancer.

\section{Heart diseases}

With nicotine being the main component of e-cigarette aerosol, ECs are also linked to spiking adrenaline, increasing blood pressure, and raising heart attack probability due to increased heart rates. Vaping also affects blood supply and coronary heart disease and increases heart disease and stroke [9]. In addition, individuals who use ECs have a 44 percent greater chance of blood clots and other circulatory complications [9]. The compounds used in e-cigarettes have been linked to an increase in cholesterol accumulation in the bloodstream, leading to clots, pulmonary instability, and potentially rapturing or heart attacks [10]. Altogether, ECs have the protentional of causing heart diseases.

\section{Respiratory diseases}

The respiratory system can be damaged due to exposure to EC's aerosol containing various chemicals through a series of mechanisms [11]. For instance, the cystic fibrosis transmembrane conductance (CFTR) in the airways is regulated by nicotinic acetylcholine receptors, which can be affected by nicotine inhalation. As a result, inhaling nicotine-containing aerosols may impair this mechanism because the enzyme is responsible for absorbing the substance into the bloodstream, leading to the impairment of the CFTR function. The loss of CFTR activity has been linked to the progression of asthma, hypertension, and chronic obstructive pulmonary disease (COPD).

\section{Methodology}

In this argumentative literature review, we discuss aspects between commonly found ingredients in e-cigarettes and their potential to produce toxicity. For our searches, we used the University of Nevada (UNR) library "OneSearch," to search for 53 references among 600 million books, e-books, scholarly articles. It includes; items physically located at the UNR libraries and research databases; E-journal articles, e-books, streaming media, and other subscription content. Criteria, terms, or phrases used in our searches included: e-cigarettes, nicotine, propylene glycol, flavorings, glycerin, vitamin E, heavy metals, lung injury, cancer, etc. Google search and scholar were also used to search for peer-reviewed papers on e-cigarettes toxicity.

\section{Commonly Found Ingredients in E-Cigarettes and Their Known Toxicity}

\section{Nicotine}

Nicotine is a naturally occurring alkaloid present in plants such as potato, tomato, eggplant, green papers, and of course, tobacco. Its IUPAC name is 3[(2S)-1-methylpyrrolidin-2-yl] pyridine with a chemical formula of $\mathrm{C}_{10} \mathrm{H}_{14} \mathrm{~N}_{2}$. Generally speaking, nicotine is the most common ingredient in EC, even though it is 
believed that EC delivers less nicotine than TC [12].

Another definition of nicotine is a stimulant drug that fastens the communication between the brain and the body [13]. In other words, when consuming a high dose of nicotine can result in either ganglionic stimulation or blockage of the ganglion as it is a stimulant to the central nervous system. It acts as an agonist to the nicotinic cholinergic receptors in the adrenal medulla, neuromuscular junction, and brain [14]. Unfortunately, nicotine is one of the most heavily abused drugs in the United States and is as addictive as other serious drugs. Therefore, it is required by the Federal Drug Agency to label all tobacco products containing nicotine with a warning and exact concentration. However, some e-liquid manufacturers mislead consumers by advertising some of their products as nicotine-free e-liquid. A study done in Malaysia found that 9 out of 35 examined nicotine-free labeled e-liquids contain nicotine. In contrast, others contain even higher nicotine concentration than what has been written on the label [15] [16]. There is no doubt that knowing the exact concentration of nicotine a person is consuming is essential to avoid reaching the toxic level of inhaled nicotine via those ECs. Unfortunately, the trend of misleading advertising regarding concentration is not limited to nicotine only, but also to other EC's ingredients [15] [16]. Therefore, there is no standard on concentration level of EC's ingredients, and it depends on the manufacture.

Nicotine's toxicity is well studied; however, most studies were performed in laboratory animals, leading to a suggestion of lethal nicotine dose at $50 \%$ of a population $\left(\mathrm{LD}_{50}\right)$ in humans. For example, in rats, the oral $\mathrm{LD}_{50}$ is $50 \mathrm{mg} / \mathrm{kg}$, while it is $9.2 \mathrm{mg} / \mathrm{kg}$ in dogs and 3.34 in mice [17]. All data together suggest the $\mathrm{LD}_{50}$ in humans is $60 \mathrm{mg}$ or even lower $(>30 \mathrm{mg}$ ) for average-sized adults. This $60 \mathrm{mg}$ corresponds to an oral $\mathrm{LD}_{50}$ of $0.8 \mathrm{mg} / \mathrm{kg}$, smaller than the one determined for laboratory mice and other animals [18]. Therefore, an overdose of nicotine is toxic and associated with some symptoms such as vomiting, sudden death, and a higher heart rate [18]. The CDC also states that there is no available data on acute inhalation toxicity of nicotine, which was predicted to be $5 \mathrm{mg} / \mathrm{m}^{3}$ based on the oral toxicity available data [18]. The lower suggested $\mathrm{LD}_{50}$ for inhalation logically makes sense since the respiratory system is susceptible. Nicotine's respiratory absorption is very rapid compared to other systems and could reach up to 80 [18]. This rapid absorption is due to the alveoli's huge surface area, which also depends on the nicotine concentration [19]. Therefore, the aerosol is quickly absorbed into the bloodstream within ten minutes after a person inhales it, and it starts affecting the brain. The chemicals trigger a reaction that produces a brief sense of concentration and satisfaction that lasts just a few minutes before dissipating. The responses include the release of adrenaline, resulting in increased heart rate, shallow breathing, and a feeling of racing heartbeats.

Many health issues could be a result of the long-term toxicity of nicotine. For instance, nicotine can cause blood vessels to constrict, increasing blood pressure and pulse. Moreover, inhaling large amounts of nicotine can result in nicotine poisoning, characterized by seizures, nausea, vomiting, and slowed breathing. 
Furthermore, the drug has been harmful to the liver, lungs, and reproductive system. The $\mathrm{pH}$ of protonated nicotine used in e-liquids is 6.0, meaning it can stimulate the nicotinic acetylcholine receptors in the epithelium. This alteration could lead to a reaction in the lungs and contribute to the initiation, development, and proliferation of lung cancer [20].

Further, when inhaled nicotine is absorbed into the bloodstream, its $\mathrm{pH}$ can influence the inner parts of the respiratory system and other body systems. Nicotine inhalation can also bind to particular receptors in the stem cell membrane of the brain, causing cells to open up to foreign ions and, ultimately, calcium overload. This might result in the cell changing their morphology affecting their functions, causing neurodegenerative illnesses and accelerated aging [21].

Despite its toxic effects, nicotine was once used as an insecticide; but it declined after introducing more potent and inexpensive substitutes [22]. Furthermore, many studies suggested that Parkinson's disease has been associated with lower rates for those who smoke compared to nonsmokers. Nicotine also improves brain function for those suffering from depression, schizophrenia, and anxiety disorders. Lastly, there is an attempt by some drug companies to study whether nicotine-containing compounds could be used to create a new medication for ADHD.

\section{Propylene glycol (PG)}

Propylene glycol in fact, constitutes $>65 \%$ of EC formulation. PG is a laboratory-made chemical by mixing chlorinated water and propylene, then treated with sodium carbonate to convert it to glycol. It is a colorless, tasteless, odorless, clear syrup liquid with the IUPAC name 1,2-dihydroxypropane, 1,2-propanediol [23]. The chemical formula of $\mathrm{PG}$ is $\mathrm{CH}_{3} \mathrm{C}_{\mathrm{H}} \mathrm{OHCH}_{2} \mathrm{OH}$.

Propylene glycol is considered a safe ingredient; therefore, pharmaceutical, food, and cosmetic industries use PG to maintain the required moisture level and absorb extra water. This substance is also used as a solvent in intravenous medications, oral syrups, nutritional colors, flavors, and paints. In ECs, Propylene glycol functions as a humectant to produce aerosol simulating smoke [15]. However, PG could be slightly hazardous when inhaled. A study found that when rats inhaled $25 \mathrm{mg} / \mathrm{kg} /$ day of PG for a length of four days, they showed some respiratory arrests as side effects on the third day [24].

Similarly, bleeding around the eyes was observed in rats in an acute inhalation study after being exposed to $214 \mathrm{mg} / \mathrm{kg}$ of PG [25]. Such results suggest that PG's inhalation might have potential toxicity, especially when consumed in higher concentrations. Therefore, even though the FDA listed PG as safe for ingestion purposes, PG's inhalation could have slight toxicity in humans.

After inhaling aerosolized propylene glycol for one minute, several people have indicated irritation [11]. Symptoms of lipoid pneumonia such as fever, productive cough, and labored breathing are linked to the compound, as well as a higher risk of developing asthma. Propylene glycol enters the body through the mucous membrane, the skin, or a topical solution and then passes to the kidneys, where most of the material is excreted. The remainder is removed from the body 
and converted to acetone and/or pyruvic acid by the liver [11]. Hence, inhalation of propylene glycol from ECs adds more stress on these critical organs, and any deficiency in one of the two can also lead to toxicity. Therefore, high doses of the PG consumed intravenously or through inhalation can have a toxic effect on humans via different mechanisms.

\section{Glycerin}

Glycerin is a colorless oily liquid with a slightly sweet taste with an IUPAC name of 1,2,3-propanetriol and a chemical formula of $\mathrm{C}_{3} \mathrm{H}_{8} \mathrm{O}_{3}$ [26]. This chemical is naturally occurring from sources like oils and fats. Like PG, it is also used in EC to simulate smoke. Furthermore, the compound is used in various personal care products such as cosmetics, toothpaste, and skin moisturizer. It has also been used in cakes, candies, cheese, meat, and drugs, both prescription and over the counter.

Similar to PG, the FDA generally views glycerin as safe with extremely low oral toxicity. As most EC's ingredients, glycerin's toxicity has not been well studied in humans; therefore, the low toxicity prediction does not indicate that it is safe when consumed over a long time through inhalation. Glycerin was also reported to have the potential of forming toxic compounds when heated at a high temperature [27]. In a study to look specifically at PG and glycerin's possible toxicity, it was found that exposure to EC that contains PG and glycerin, combined or separated, leads to pulmonary transcriptional alteration in genes of the circadian molecular clock [28]. In the study, mice were exposed to nicotine-free, flavor-free PG and glycerin vapor for eight weeks to ensure that the results were not due or linked to nicotine or/and chemical flavors.

Furthermore, high glycerin levels seem to affect spermatogenesis and reproductive health in males significantly [11]. Continuous use of glycerol and propylene glycol can gradually lead to pulmonary inflammation over time [29]. Also, inhaling glycerin affects the lung tissues and may irritate the airways. Nevertheless, the available data of both PG and glycerin's possible toxicity drive some manufacturers to use ethylene glycol as an alternative option.

\section{Ethylene glycol (EG)}

Another component found in e-liquid as a solvent is ethylene glycol, a colorless, odorless, slightly viscous property. Ethylene glycol is commonly used as antifreeze in e-liquid as an industrial solvent. As mentioned above, it is used as an alternative to propylene glycol and glycerol after the increase of awareness on propylene glycol and glycerol's toxicities. Since most ethylene glycol toxicity cases are through acute poisoning and oral, the predicted $\mathrm{LD}_{50}$ in humans is 1600 $\mathrm{mg} / \mathrm{kg}$ [30]. Exposure to EG via ingestion could lead to systemic toxicity [31]. This compound is known to be associated with metabolic acidosis, associated with cardiovascular collapse, seizures, and respiratory suppression. In general, ethylene glycol's toxicity is very low through oral, dermal, and inhalation; however, data on its toxicity is minimal and more research should be done on that matter. 


\section{Vitamins}

Interestingly, some e-liquids contain vitamins and advertise EC as "vitamin Delivery Devices" [32]. One of the most vitamins found in e-liquid is vitamin E acetate, which is used as an antioxidant in the EC industry. Vitamin E is a fatsoluble nutrient found in many products such as foods, hair/body products. In the human body, vitamin $\mathrm{E}$ acts as an antioxidant to protect cells from the damage caused by free radicals [33]. Commonly, Vitamin $\mathrm{E}$ is safe to be consumed orally or through the skin; however, it might be toxic if consumed through inhalation. Research has associated vitamin E with EVALI, a lung disease linked to vaping presented as chest pains, trouble breathing, gastrointestinal discomfort, and ultimately lung damage [34].

Similarly, Blount and his group conclude that Vitamin E acetate is linked to EVALI when they studied samples from 51 patients with EVALI in 16 states [35]. The number of lung injury cases caused by vaping peaked in September of 2019, with vitamin E acetate being a prominent compound found in the fluids of those suffering from the disease [6]. Furthermore, a previous opinion paper describes the possibility of vitamin $\mathrm{E}$ acting as a pro-oxidant, leading to serious health issues. When Vitamin E acetate is inhaled, it enters an oxygen-rich environment, the lungs. The antioxidant vitamin could exhibit pro-oxidant effects due to a high level of oxygen through possible side reactions [36]. As the awareness of vitamin E toxicity in ECs has been rising, many states have banned vitamin E acetate in any of the ECs products [36].

\section{Flavorings}

Hundreds of flavors are used daily to recreate a taste of desire in many products such as food, drugs, and EC's e-liquids. Some of these flavors are natural, while others are artificial and chemical. Generally, those chemical flavors are classified as GRAS, meaning they are generally recognized as safe by the FDA. However, this recognition is only limited to ingestion but no other entry routes such as inhalation, as is the case with ECs. Examples of the most used chemical flavors used in e-liquid are ethyl maltol (caramelized sugary \& cooked fruity taste), diacetyl (buttery taste), butanoic acid ethyl ester (fruity taste), vanillin (vanilla taste), and many others. Due to these varieties of flavors, uptake of these devices among the youth has increased.

The toxicity of flavorings depends on the specific chemical used. For example, diacetyl is a ubiquitous artificial flavor that produces a buttery flavor in many food products such as popcorn. Before ECs, inhalation exposure of diacetyl was limited to occupational settings such as working in a factory of microwave popcorn packing plants [37]. In respiratory toxicity of diacetyl study, male mice exposed to inhaled diacetyl show significant epithelial injury, inflammation, or fibrohistiocytic lesions in the terminal bronchioles depending on the concentration and length of exposure [37]. Furthermore, inhalation of vanillin and chocolate favoring 2,5-dimethylhydrazine via vapors causes an alteration in the cellular physiology indicative of cellular signaling event via activation of the cystic fibrosis trans-member conductance regulator ion channel [38]. When used in large 
doses, some flavorings can cause inflammation, free radical development, subsequent DNA damage, and cell death. In addition, propylene glycol solvent found in e-liquid may react with the flavor molecules, generating intermediate substances and metabolites that can irritate the nasal cavity and respiratory system [11]. Even though most flavorings seem non-toxic when ingested, more studies are needed to look at their potential inhalation toxicity.

\section{Particulates and Metals}

The design of ECs devices, especially the heating elements, seems responsible for emitting some toxic metallic particles such as nickel, chromium, lead, manganese, and tin [39]. These metals are well-recognized as toxic or harmful to humans by the FDA. In 2013, Monique Williams and his colleagues studied one EC brand and looked deeply for the preset of nanoparticles and metals produced by this device. Twenty-two elements were identified in their study, including those mentioned above. One of their findings was that nickel level, for instance, is $2-100$ times higher than the amount found in TC's smoke, while lead and chromium level is similar to TC's smoke [40].

Nickel's toxicity is characterized by oxidative stress and inflammation in the lung when tested on mice after long-term inhalation exposure of nickel [41]. On the other hand, Chromium's toxicity is linked to reduced lung functions in humans when inhaled [39]. Lead and manganese are also toxic when inhaled as lead is absorbed into the bloodstream rapidly while it is linked to neurological symptoms [39]. Tin also was found to be cytotoxic to human lung fibroblasts. Nevertheless, the concentration level of these metals in EC's aerosol depends on the device brands and their quality. However, most of them show some level of presented metals, which is a health concern for vapor consumers [42].

\section{Effect of Ingredient Volatilization}

Ingredient volatilization might lead to toxic aldehydes formation. In general, high temperature is required for these aldehydes to form. Depending on the EC device generation, some devices had made it to reach that level of temperature. Examples of these aldehydes include formaldehyde, acetaldehyde, and acrolein.

Formaldehyde

Formaldehyde is a colorless naturally occurring aldehyde with an IUPAC name of methanol. It is listed as a toxic compound that is linked to cancer. Formaldehyde concentration in the air should be around 80 parts per billion to be considered acceptable [43]. Thermo-degradation of glycerol is the source of formaldehyde in ECs; as the glycerol heats up at a high temperature, they might form this toxic compound [27]. According to the American Cancer Society, inhaled formaldehyde was associated with cancers of the nasal cavity and leukemia when laboratory animals were exposed [44]. In a recent study, 2018, a new form of formaldehyde was detected in ECs. This new form of formaldehyde, formaldehyde hemiacetals, seems to reach more profound in the lungs when inhaled [45]. Formaldehyde hemiacetals' ability to reach deep into the lungs when inhaled 
may lead to more severe health concerns.

\section{Acetaldehyde}

Acetaldehyde is a highly reactive and toxic compound that is naturally occurring. It is found in bread, coffee, ripe fruit, and some plants, with ethanal as IUPAC name. Acetaldehyde is known to be an abundant carcinogen in tobacco smoke [46]. In ECs, acetaldehyde content ranges from 1.1 to $13.6 \mu \mathrm{g}$ per 150 puffs of vapors [47]. One breath of EC contains a range of $0.022 \pm 0.008$ to 22.5 $\pm 6.2 \mu \mathrm{g}$ of acetaldehyde [48]. The toxicity of acetaldehyde is well-studied and determined to be carcinogenic and cytotoxic. When rats were exposed to inhaled acetaldehyde, they showed nasal tumors [49]. In addition, acetaldehyde inhalation was found to be linked to nasopharyngeal and laryngeal carcinoma [49] [50].

\section{Acrolein}

Acrolein is an alpha-beta-unsaturated aldehyde with an IUPAC name of 2propenal. It is listed as a hazardous air pollutant by the US EPA. The formation of Acrolein is via overheating cooking oils. In ECs, acrolein is formed due to the thermo-degradation of glycerol [51]. Formation of Acrolein ranges between 0.7 $41.9 \mu \mathrm{g}$ in every 150 puffs of ECs [47]. In an acrolein review paper by Bein and Leikauf, inhalation exposure to Acrolein leads to many health issues, including lung cancer, asthma, and COPD. When inhaling a high concentration of Acrolein, acrolein can adduct tumor suppressor p53 DNA leading to a potential mutation in lung cancer [52]. In addition, exposure to Acrolein could irritate the nasal cavity [53].

\section{Conclusion}

E-cigarettes are a relatively new phenomenon, initially introduced to help smokers reduce their tobacco intake; the devices have become increasingly abused, especially by the youth. The toxicity of e-cigarettes ingredients is not well established when inhaled. The main ingredients are nicotine, propylene glycol, glycerol, ethylene glycol, vitamin E, flavorings, and heavy metals, each with a potentially harmful effect on the human's health. E-cigarettes aerosol could also contain toxic compounds such as formaldehyde, acetaldehyde, and acrolein due to glycerin's thermo-degradation. Despite the limited knowledge of vaping's health effects, recent studies have linked e-cigarettes ingredients to some health problems such as lung injury, cancers, heart and respiratory diseases. It is worth noting that vaping systems have changed regular cigarettes by removing the most harmful compounds that make smoking much riskier than vaping. However, future research efforts should be directed to studying the toxicity of E-cigarette ingredients when inhaled.

\section{Conflicts of Interest}

The authors declare no conflicts of interest regarding the publication of this paper. 


\section{References}

[1] Callahan-Lyon, P. (2014) Electronic Cigarettes: Human Health Effects. Tobacco Control, 23, ii36-ii40. https://doi.org/10.1136/tobaccocontrol-2013-051470

[2] National Institute on Drug Abuse (2020) Vaping Devices (Electronic Cigarettes) DrugFacts.

https://www.drugabuse.gov/publications/drugfacts/vaping-devices-electronic-cigare $\underline{\text { ttes }}$

[3] FDA (U.S. Food and Drug Administration) (2020) Vaporizers, E-Cigarettes, and other Electronic Nicotine Delivery Systems (ENDS).

https://www.fda.gov/tobacco-products/products-ingredients-components/vaporizer s-e-cigarettes-and-other-electronic-nicotine-delivery-systems-ends

[4] Texas Department of State Health Services (2021) What Is Vaping? https://www.dshs.state.tx.us/Vaping/WhatisVaping/

[5] ASAM (American Society of Addiction Medicine) (2020) E-Cigarettes. https://www.asam.org/advocacy/find-a-policy-statement/view-policy-statement/pu blic-policy-statements/2020/04/01/e-cigarettes

[6] Center for Disease Control and Prevention (2021) Electronic Cigarettes. https://www.cdc.gov/tobacco/basic information/e-cigarettes/index.htm

[7] Daynard, R. (2018) Public Health Consequences of E-Cigarettes: A Consensus Study Report of the National Academies of Sciences, Engineering, and Medicine. Journal of Public Health Policy, 39, 379-381. https://doi.org/10.1057/s41271-018-0132-1

[8] National Institute of Health (2019) E-Cigarette Vapor Linked to Cancer in Mice. https://www.nih.gov/news-events/nih-research-matters/e-cigarette-vapor-linked-ca ncer-mice

[9] Vindhyal, M.R., Ndunda, P., Munguti, C., Vindhyal, S. and Okut, H. (2019) Impact on Cardiovascular Outcomes among E-Cigarette Users: A Review from National Health Interview Surveys. Journal of the American College of Cardiology, 73, 11. https://doi.org/10.1016/S0735-1097(19)33773-8

[10] Kuehn, B.M. (2017) Emerging Data Show E-Cigarettes May Pose Heart Risk. Circulation, 136, 232-233. https://doi.org/10.1161/CIRCULATIONAHA.117.029532

[11] Eaton, D.L., et al. (2018) Toxicology of E-Cigarette Constituents. In: Eaton, D.L., Kwan, L.Y. and Stratton, K., Eds., Public Health Consequences of E-Cigarettes, National Academies Press (US), Washington DC, 155-215.

[12] Elkalmi, R.M., Bhagavathul, A.S., Ya'u, A., Al-Dubai, S.A.R., Elsayed, T.M., Ahmad, A., et al. (2016) Familiarity, Perception, and Reasons for Electronic-Cigarette Experimentation among the General Public in Malaysia: Preliminary insight. Journal of Pharmacy and Bioallied Sciences, 8, 240-247.

https://doi.org/10.4103/0975-7406.180768

[13] ADF (Alcohol and Drug Foundation) (2021) Nicotine. https://adf.org.au/drug-facts/nicotine/

[14] NCBI (National Center for Biotechnology Information) Nicotine. https://pubchem.ncbi.nlm.nih.gov/compound/Nicotine

[15] Naeem, M.N.M., Zain, S.M.S.M., Ng, C. and Noh, M.F.M. (2020) Chemical Constituents in E-Cigarette Liquids and Aerosols. Journal of Environmental Protection, 11, 664-681. https://doi.org/10.4236/jep.2020.119040

[16] Zain, S.M.S.M., Khair, S.K.J., Mohamad, N., Noh, M.F.M. and Radhakrishnan, D.A. (2019) Nicotine Content in Electronic Cigarette Refill Solutions and Its Release in Aerosols. Journal of Environmental Protection, 10, 1317-1332. 
https://doi.org/10.4236/jep.2019.1010078

[17] Center for Disease Control and Prevention (2014) Immediately Dangerous to Life or Health Concentrations (IDLH): Nicotine. NIOSH Publications and Products. https://www.cdc.gov/niosh/idlh/54115.html

[18] Mayer, B. (2014) How Much Nicotine Kills a Human? Tracing Back the Generally Accepted Lethal Dose to Dubious Self-Experiments in the Nineteenth Century. Archives of Toxicology, 88, 5-7. https://doi.org/10.1007/s00204-013-1127-0

[19] Karačonji, I.B. (2005) Facts about Nicotine Toxicity. Arhiv za higijenu rada i toksikologiju, 56, 363-371.

[20] Shao, X.S.M. and Friedman, T.C. (2020) Pod-Mod vs. Conventional E-Cigarettes: Nicotine Chemistry, pH, and Health Effects. Journal of Applied Physiology, 128, 1056-1058. https://doi.org/10.1152/japplphysiol.00717.2019

[21] Zahedi, A., Phandthong, R., Chaili, A., Leung, S., Omaiye, E. and Talbot, P. (2019) Mitochondrial Stress Response in Neural Stem Cells Exposed to Electronic Cigarettes. iScience, 16, 250-269. https://doi.org/10.1016/j.isci.2019.05.034

[22] Mishra, A., Chaturvedi, P., Datta, S., Sinukumar, S., Joshi, P. and Apurva, G. (2015) Harmful Effects of Nicotine. Indian Journal of Medical and Paediatric Oncology, 36, 24-31. https://doi.org/10.4103/0971-5851.151771

[23] NCBI (National Center for Biotechnology Information) Propylene Glycol. https://pubchem.ncbi.nlm.nih.gov/compound/1030

[24] Montharu, J., Le Guellec, S., Kittel, B., Rabemampianina, Y., Guillemain, J., Gautheir, F., et al. (2010) Evaluation of Lung Tolerance of Ethanol, Propylene Glycol, and Sorbitan Monooleate as Solvents in Medical Aerosols. Journal of Aerosol Medicine and Pulmonary Drug Delivery, 23, 41-46.

https://doi.org/10.1089/jamp.2008.0740

[25] Cotta, K.I., Stephen, C.D. and Mohammad, N.U. (2017) A Review on the Safety of Inhalation of Propylene Glycol in E-Cigarettes. Global Journal of Pharmacy \& Pharmaceutical Sciences, 2, Article ID: 555584. https://doi.org/10.19080/GJPPS.2017.02.555584

[26] NCBI (National Center for Biotechnology Information) Glycerol. https://pubchem.ncbi.nlm.nih.gov/compound/753

[27] Hajek, P., Etter, J.-F., Benowitz, N., Eissenberg, T. and McRobbie, H. (2014) Electronic Cigarettes: Review of Use, Content, Safety, Effects on Smokers and Potential for Harm and Benefit. Addiction, 109, 1801-1810.

https://doi.org/10.1111/add.12659

[28] Lechasseur, A., Huppé, C.-A., Talbot, M., Routhier, J., Aubin, S., Beaulieu, M.-J., et al. (2020) Exposure to Nicotine-Free and Flavor-Free E-Cigarette Vapors Modifies the Pulmonary Response to Tobacco Cigarette Smoke in Female Mice. American Journal of Physiology-Lung Cellular and Molecular Physiology, 319, L717-L727. https://doi.org/10.1152/ajplung.00037.2020

[29] Song, M.A., Reisinger, S.A., Freudenheim, J.L., Brasky, T.M., Mathé, E.A., McElroy, J.P., et al. (2020) Effects of Electronic Cigarette Constituents on the Human Lung: A Pilot Clinical Trial. Cancer Prevention Research, 13, 145-151. https://doi.org/10.1158/1940-6207.CAPR-19-0400

[30] Hess, R., Bartels, M.J. and Pottenger, L.H. (2004) Ethylene Glycol: An Estimate of Tolerable Levels of Exposure Based on a Review of Animal and Human Data. Archives of Toxicology, 78, 671-680. https://doi.org/10.1007/s00204-004-0594-8

[31] What Are Routes of Exposure to Ethylene Glycol? 
https://www.atsdr.cdc.gov/csem/ethylene-propylene-glycol/exposure pathways.html

[32] Basanez, T., Majmundar, A., Cruz, T.B., Allem, J.P. and Unger, J.B. (2019) E-Cigarettes Are Being Marketed as "Vitamin Delivery" Devices. American Journal of Public Health, 109, 194-196. https://doi.org/10.2105/AJPH.2018.304804

[33] Office of Dietary Supplements-Vitamin E. https://ods.od.nih.gov/factsheets/VitaminE-HealthProfessional/

[34] Boudi, F.B., Patel, S., Boudi, A. and Chan, C. (2019) Vitamin E Acetate as a Plausible Cause of Acute Vaping-Related Illness. Cureus, 11, Article No. e6350. https://doi.org/10.7759/cureus.6350

[35] Blount, B.C., Karwowski, M.P., Shields, P.G., Morel-Espinosa, M., Valentin-Blasini, L., Gardner, M., et al. (2020) Vitamin E Acetate in Bronchoalveolar-Lavage Fluid Associated with EVALI. New England Journal of Medicine, 382, 697-705. https://doi.org/10.1056/NEJMoa1916433

[36] Omaye, S.T. (2019) Biomedres. Biomedical Journal of Scientific \& Technical Research, Article ID: 17755.

[37] Morgan, D.L., Flake, G.P., Kirby, P.J. and Palmer, S.M. (2008) Respiratory Toxicity of Diacetyl in C57Bl/6 Mice. Toxicological Sciences, 103, 169-180. https://doi.org/10.1093/toxsci/kfn016

[38] Sherwood, C.L. and Boitano, S. (2016) Airway Epithelial Cell Exposure to Distinct E-Cigarette Liquid Flavorings Reveals Toxicity Thresholds and Activation of CFTR by the Chocolate Flavoring 2,5-Dimethypyrazine. Respiratory Research, 17, Article No. 57. https://doi.org/10.1186/s12931-016-0369-9

[39] Hess, C.A., Olmedo, P., Navas-Acien, A., Goessler, W., Cohen, J.E. and Rule, A.M. (2017) E-Cigarettes as a Source of Toxic and Potentially Carcinogenic Metals. Environmental Research, 152, 221-225. https://doi.org/10.1016/j.envres.2016.09.026

[40] Williams, M., Villarreal, A., Bozhilov, K., Lin, S. and Talbot, P. (2013) Metal and Silicate Particles Including Nanoparticles Are Present in Electronic Cigarette Cartomizer Fluid and Aerosol. PLoS ONE, 8, Article ID: e57987.

https://doi.org/10.1371/journal.pone.0057987

[41] Kang, G.S., P. Gillespie, A., Gunnison, A., Moreira, A.L., Tchou-Wong, K.M. and Chen, L.C. (2011) Long-Term Inhalation Exposure to Nickel Nanoparticles Exacerbated Atherosclerosis in a Susceptible Mouse Model. Environmental Health Perspectives, 119, 176-181. https://doi.org/10.1289/ehp.1002508

[42] Williams, M., To, A., Bozhilov, K. and Talbot, P. (2015) Strategies to Reduce Tin and Other Metals in Electronic Cigarette Aerosol. PLoS ONE, 10, Article ID: e0138933. https://doi.org/10.1371/journal.pone.0138933

[43] Farsalinos, K.E., Voudris, V. and Poulas K. (2015) E-Cigarettes Generate High Levels of Aldehydes Only in 'Dry Puff' Conditions. Addiction, 110, 1352-1356.

https://doi.org/10.1111/add.12942

[44] Cancer.org (2014) Formaldehyde.

https://www.cancer.org/cancer/cancer-causes/formaldehyde.html

[45] Salamanca, J.C., Meehan-Atrash, J., Vreeke, S., Escobedo, J.O., Peyton, D.H. and Strongin, R.M. (2018) E-Cigarettes Can Emit Formaldehyde at High Levels under Conditions That Have been Reported to Be Non-Averse to Users. Scientific Reports, 8, Article No. 7559. https://doi.org/10.1038/s41598-018-25907-6

[46] NCBI (National Center for Biotechnology Information) (n.d.) Acetaldehyde. https://pubchem.ncbi.nlm.nih.gov/compound/177

[47] Goniewicz, M.L., Knysak, J., Gawron, M., Kosmider, L., Sobczak, A., Kurek, J., et al. 
(2014) Levels of Selected Carcinogens and Toxicants in Vapour from Electronic Cigarettes. Tobacco Control, 23, 133-139.

https://doi.org/10.1136/tobaccocontrol-2012-050859

[48] Samburova, V., Bhattarai, C., Strickland, M., Darrow, L., Angermann, J., Son, Y., et al. (2018) Aldehydes in Exhaled Breath during E-Cigarette Vaping: Pilot Study Results. Toxics, 6, Article No. 46. https://doi.org/10.3390/toxics6030046

[49] Woutersen, R.A., Appelman, L.M., Vangarderenhoetmer, A. and Feron, V.J. (1986) Inhalation Toxicity of Acetaldehyde in Rats. 3. Carcinogenicity Study. Toxicology, 41, 213-231. https://doi.org/10.1016/0300-483X(86)90201-5

[50] Feron, V.J., Kruysse, A. and Woutersen, R.A. (1982) Respiratory-Tract Tumors in Hamsters Exposed to Acetaldehyde Vapor Alone or Simultaneously to Benzo(a)pyrene or Diethylnitrosamine. European Journal of Cancer \& Clinical Oncology, 18, 13-21, 23-31. https://doi.org/10.1016/0277-5379(82)90020-7

[51] Hutzler, C., Paschke, M., Kruschinski, S., Henkler, F., Hahn, J. and Luch, A. (2014) Chemical Hazards Present in Liquids and Vapors of Electronic Cigarettes. Archives of Toxicology, 88, 1295-1308. https://doi.org/10.1007/s00204-014-1294-7

[52] Bein, K. and Leikauf, G.D. (2011) Acrolein-A Pulmonary Hazard. Molecular Nutrition \& Food Research, 55, 1342-1360. https://doi.org/10.1002/mnfr.201100279

[53] EPA (U.S. Environmental Protection Agency) (2003) Toxicological Review of Acrolein. US Environmental Protection Agency, Washington DC.

https://cfpub.epa.gov/ncea/iris/iris documents/documents/toxreviews/0364tr.pdf 